\title{
A flavonoid chrysin suppresses hypoxic survival and metastatic growth of mouse breast cancer cells
}

\author{
KRIENGSAK LIRDPRAPAMONGKOL ${ }^{1}$, HIROAKI SAKURAI ${ }^{3,4}$, SHERIF ABDELHAMED $^{3}$, \\ SATORU YOKOYAMA $^{3}$, TAKEYUKI MARUYAMA $^{3}$, SIRIVAN ATHIKOMKULCHAI $^{7}$, AMORNRAT VIRIYAROJ $^{7}$, \\ SURESH AWALE ${ }^{5}$, HIDEO YAGITA ${ }^{6}$, SOMSAK RUCHIRAWAT ${ }^{2,8,9}$, JISNUSON SVASTI $^{1}$ and IKUO SAIKI ${ }^{3}$ \\ Laboratories of ${ }^{1}$ Biochemistry and ${ }^{2}$ Medicinal Chemistry, Chulabhorn Research Institute, Bangkok 10210, Thailand; \\ ${ }^{3}$ Division of Pathogenic Biochemistry, Institute of Natural Medicine, ${ }^{4}$ Department of Cancer Cell Biology, \\ Graduate School of Medicine and Pharmaceutical Sciences, ${ }^{5}$ Frontier Research Core for Life Sciences, \\ University of Toyama, Toyama 930-0194; ${ }^{6}$ Department of Immunology, Juntendo University School of Medicine, \\ Tokyo 113-8421, Japan; ${ }^{7}$ Faculty of Pharmacy, Srinakharinwirot University, Nakhon Nayok $26120 ;{ }^{8}$ Program in \\ Chemical Biology, Chulabhorn Graduate Institute, Bangkok 10210; ${ }^{9}$ Center of Excellence on Environmental Health \\ and Toxicology (EHT), Commission on Higher Education (CHE), Ministry of Education, Bangkok 10400, Thailand
}

Received May 27, 2013; Accepted July 15, 2013

DOI: $10.3892 /$ or.2013.2667

\begin{abstract}
Tumor hypoxia commonly occurs in solid tumors, and correlates with metastasis. Current cancer therapies are inefficient in curing metastatic disease. Herein, we examined effect of Thai propolis extract and its major constituent, chrysin, on hypoxic survival of 4T1 mouse breast cancer cells in vitro, and investigated its underlying mechanism. In vivo effect of chrysin on metastatic progression of cancer cells was studied, both as a single agent and in combination with another antimetastatic agent, agonistic monoclonal antibody targeting the DR5 TRAIL receptor (DR5 mAb). Thai propolis extract and chrysin decreased survival of 4T1 cells after exposure to hypoxia $\left(1 \% \mathrm{O}_{2}\right)$, for 2 days. Immunoblot analysis revealed that chrysin inhibited hypoxia-induced STAT3 phosphorylation without affecting HIF-1 $\alpha$ protein level. Chrysin also abrogated hypoxia-induced VEGF gene expression as determined by qRT-PCR. The in vivo effect of chrysin was determined in a spontaneous metastasis mouse model of breast cancer, either alone or in combination with DR5 mAb. Daily oral administration of chrysin in Balb/c mice implanted with 4T1 cells significantly suppressed growth of lung metastatic colonies. Moreover, antimetastatic activity of DR5 mAb was enhanced when given in combination with chrysin. We demonstrate that chrysin has potential in controlling metastatic progression.
\end{abstract}

Correspondence to: Dr Kriengsak Lirdprapamongkol, Laboratory of Biochemistry, Chulabhorn Research Institute, 54 Kamphaeng Phet 6, Laksi, Bangkok 10210, Thailand

E-mail: kriengsak@cri.or.th

Key words: antimetastatic, hypoxia, STAT3, propolis, natural products

\section{Introduction}

Metastasis is the spread of cancer in the body, by which cancer cells in the primary tumor travel to distant sites, and form metastatic colonies. Most cancer deaths are caused by the growth of metastases to form clinically harmful tumors, rather than primary tumor growth. Since current cancer therapies are inefficient in eradicating metastases, any strategy that can prevent metastatic progression or inhibits the growth of metastases in distant sites benefit patients (1). An agonistic monoclonal antibody (DR5 $\mathrm{mAb}$ ) targeting a receptor of endogenous death ligand (DR5 TRAIL receptor) can reduce the number of metastatic colonies in mouse models (2). However, the effect of combining DR5 mAb with other antimetastatic natural products has not been investigated.

A unique feature of solid tumors is the occurrence of low oxygen levels (hypoxia) in some regions within the tumor as it grows. This has received much attention as an attractive target for anticancer drug development (3). Clinical studies indicate correlation between tumor hypoxia, tumor progression and development of distant metastases $(4,5)$. The presence of hypoxia is not restricted to the primary tumor, but also appears in metastatic sites. Increasing evidence obtained from various animal models indicates avascular micrometastases ( $<1 \mathrm{~mm}$ in diameter) are hypoxic, while macrometastases (1-4 $\mathrm{mm}$ in diameter) are vascularized and not hypoxic (6-8). Tumor-induced angiogenesis is known to contribute to metastasis promotion and growth of micrometastases (9). Vascular endothelial growth factor (VEGF) is one of the most potent angiogenic factors, and its production is upregulated in hypoxic cells, further inducing angiogenesis in hypoxic tissues (10). Hypoxic adaptation is mediated by hypoxia-inducible factor (HIF)-1 which is a heterodimeric transcription factor composed of HIF- $1 \alpha$ and HIF-1 $\beta$ subunits. Although HIF-1 is the master regulator of hypoxic response, other signaling pathways including STAT3, Akt, ERK, and NF- $\mathrm{BB}$, are also activated 
by hypoxia and participate in hypoxia-induced VEGF gene expression $(10,11)$. VEGF also acts as an autocrine survival factor for breast cancer cells under hypoxia (12). Moreover, inhibition of VEGF gene expression in breast cancer cells can suppress metastasis in a mouse model (13).

Propolis (bee glue) is a resinous material that honeybees collect from various plants, and is a rich source of bioactive compounds. Several HIF-1 modulating compounds have been isolated from Brazilian green propolis, indicating the potential of propolis as a source of hypoxic modulating compounds (3). We have isolated a flavonoid chrysin (5,7-dihydroxyflavone) from Thai propolis extract as a major constituent. Chrysin has been shown to possess multiple bioactivities. Inhibition of subcutaneous tumor growth by chrysin has recently been demonstrated in mouse models of breast cancer and hepatoma $(14,15)$. Chrysin has also been shown to suppress hypoxia-induced VEGF expression in human prostate cancer cells in vitro (16), and abrogates tumor-induced angiogenesis in vivo $(15,16)$. However, until now, there has been no report on the effect of chrysin on hypoxic survival and metastatic progression of cancer cells.

In this study, we demonstrate the inhibitory effect of chrysin on hypoxic survival of mouse breast cancer cells in vitro, and also investigate its mechanism of action. We also studied the in vivo effect of chrysin in a spontaneous metastasis model of breast cancer, both as a single agent and in combination with DR5 mAb.

\section{Materials and methods}

Chemicals and antibodies. Protease inhibitor cocktail for use with mammalian cells and tissue extracts was obtained from Sigma-Aldrich (St. Louis, MO, USA). Chrysin was purchased from Alexis Biochemicals (San Diago, CA, USA). Specific inhibitors of STAT3 (Cucurbitacin-I), PI3K (LY294002), ERK (PD98059), and NF- $\mathrm{B}$ (IKK-2 inhibitor IV) were obtained from Calbiochem (San Diego, CA, USA). For in vitro experiments, test compounds were dissolved in dimethyl sulfoxide (DMSO) and kept as a stock solution at $-20^{\circ} \mathrm{C}$. The final concentration of DMSO was kept below $0.2 \%$ throughout the study. Primary antibodies specific to Tubulin, STAT3, Akt, ERK1/2, and p65 NF- $\mathrm{BB}$ and phosphorylated forms of STAT3 (Tyr705), Akt $\left(\mathrm{Ser}^{473}\right)$, ERK1/2 $\left(\mathrm{Thr}^{202} / \mathrm{Tyr}^{204}\right)$, p65 NF-кB $\left(\mathrm{Ser}^{536}\right)$ were purchased from Cell Signaling Technology (Beverly, MA, USA). Primary antibody specific to HIF-1 $\alpha$ (H1 $\alpha 67)$ was obtained from Novus Biologicals (Littleton, $\mathrm{CO}$, USA). Agonistic monoclonal antibody targeting mouse DR5 TRAIL receptor (DR5 mAb or MD5-1) was obtained from the Department of Immunology, Juntendo University School of Medicine, Japan.

Propolis extraction and isolation of compounds. Thai propolis was harvested from a hive of Apis mellifera collected in Chiangmai province, Thailand, in August 2006. A voucher specimen (SWU 0212) was deposited at the Faculty of Pharmacy, Srinakharinwirot University, Nakhon Nayok province, Thailand. Two major compounds, chrysin and tectochrysin, were isolated. Propolis $(1 \mathrm{~kg})$ was extracted with methanol $(\mathrm{MeOH})$ under sonication yielding $517 \mathrm{~g}$ extract. Part of the extract (140 g) was fractionated by silica gel column chromatography using dichloromethane $\left(\mathrm{CH}_{2} \mathrm{Cl}_{2}\right)$, with increasing concentration of $\mathrm{MeOH}$, to obtain 16 fractions. Fraction 5 (3.0 g, 1-1.5\% $\mathrm{MeOH}-\mathrm{CH}_{2} \mathrm{Cl}_{2}$ eluate) and fraction 8 (9.5 g, $2 \% \mathrm{MeOH}-\mathrm{CH}_{2} \mathrm{Cl}_{2}$ eluate) was left overnight to obtain the crystals of tectochrysin $(314 \mathrm{mg})$ and chrysin $(732 \mathrm{mg})$, respectively. Their structures were identified by comparison of physical and spectroscopic data with authentic standard and the published data $(17,18)$.

Cell culture. 4T1 murine mammary carcinoma cell line was obtained from the American Type Culture Collection (ATCC, Rockville, MD, USA). Cells were cultured in DMEM supplemented with $2 \mathrm{mM}$ L-glutamine, $10 \%$ fetal bovine serum (FBS) and antibiotics, and maintained at $37^{\circ} \mathrm{C}$ in a humidified atmosphere of $5 \% \mathrm{CO}_{2}$ : these conditions were used as normoxic condition $\left(21 \% \mathrm{O}_{2}\right)$. For hypoxic condition $\left(1 \% \mathrm{O}_{2}\right)$, the cells were incubated at $37^{\circ} \mathrm{C}$, in a humidified atmosphere of $1 \% \mathrm{O}_{2}$ and $5 \% \mathrm{CO}_{2}$ maintained by a regulated supply of $\mathrm{N}_{2}$ and $\mathrm{CO}_{2}$ gas inside a hypoxic chamber (C-Chamber with ProOX and $\mathrm{ProCO}_{2}$ controllers, Biospherix, NY, USA).

Hypoxic cell survival assay. Cells were seeded into 96-well plates $\left(5 \times 10^{3}\right.$ cells/well) and left overnight in a $\mathrm{CO}_{2}$ incubator. The cells were pretreated by adding medium containing test compound to the wells, and incubated for $30 \mathrm{~min}$, then the plates were further incubated under hypoxia $\left(1 \% \mathrm{O}_{2}\right)$ for $48 \mathrm{~h}$. Number of surviving cells after treatment was determined by crystal violet staining method as previously described (19). Briefly, the cells were washed three times with phosphate buffer saline (PBS), fixed with 95\% ethanol, and stained with crystal violet solution $(0.5 \% \mathrm{w} / \mathrm{v}$ in $25 \% \mathrm{MeOH})$. After extensive washing by tap water, the stained cells were lysed with $0.1 \mathrm{~N} \mathrm{HCl}$ in $\mathrm{MeOH}$, after which absorbance was determined at $550 \mathrm{~nm}$ using a microplate reader. Assay was performed in triplicate wells, and results were expressed as percent survival compared with control (DMSO).

Immunoblot analysis. After treatment, cells were rinsed with cold PBS, scraped and lysed in RIPA lysis buffer containing phosphatase inhibitors $(20 \mathrm{mM} \beta$-glycerophosphate, $1 \mathrm{mM}$ $\mathrm{Na}_{3} \mathrm{VO}_{4}, 10 \mathrm{mM} \mathrm{NaF}$ ) and protease inhibitor cocktail. Cell lysates were fractionated by electrophoresis in $7.5 \%$ or $10 \%$ SDS-PAGE, and electrophoretically transferred to PVDF membrane (Immobilon-P nylon, Millipore, Bedford, MA, USA). After blocking with BlockAce (Dainippon Pharmaceutical, Co. Ltd., Osaka, Japan), the membranes were probed with the indicated primary antibodies overnight, followed by horseradish peroxidase-conjugated secondary antibodies. Bands were visualized using WesternBright ECL reagent (Advansta, Menlo Park, CA, USA).

Quantitative reverse transcriptase-polymerase chain reaction ( $q R T-P C R)$. RNA extraction and first-strand cDNA synthesis were performed as previously described (20). Real-time PCR was run on a LightCycler ${ }^{\circledR} 2.0$ Instrument (Roche), using QuantiTect $^{\mathrm{TM}}$ SYBR Green PCR Master mix (Qiagen, Valencia, CA, USA). Sequences of PCR primers were obtained from following references; mouse VEGF (21); mouse $\beta$-actin (22). VEGF primer (fwd) 5'-GAGATGAGCTTCCTA CAGCAC-3'; and VEGF primer (rev) 5'-TCACCGCCTTGG 

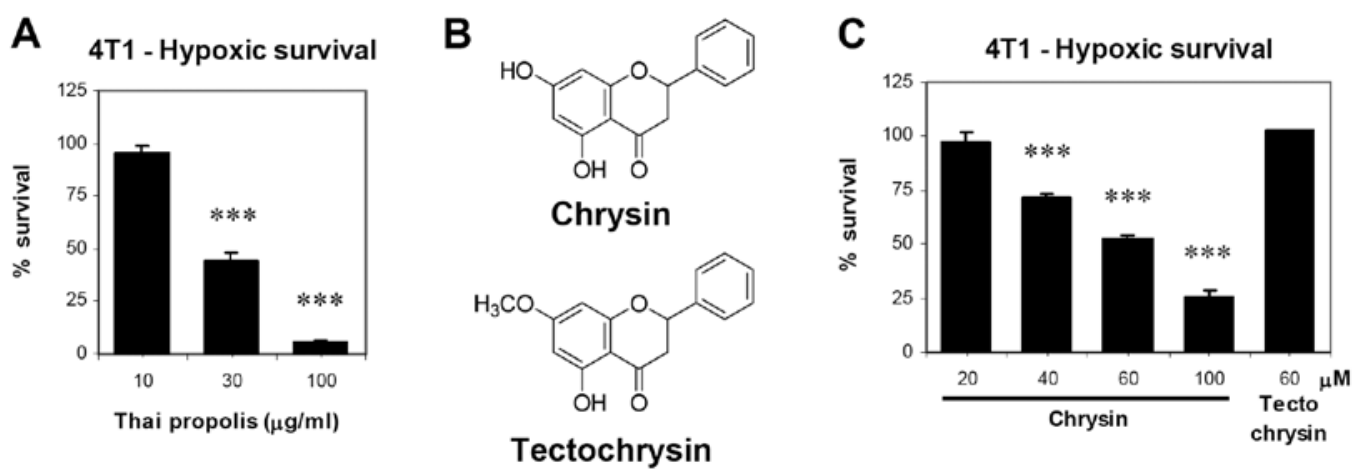

Figure 1. Inhibitory effect of Thai propolis extract and its major constituents on hypoxic survival of 4T1 cells. (A and C) Cells in the 96-well plate were treated with Thai propolis extract, chrysin and tectochrysin for $30 \mathrm{~min}$ before incubation under hypoxic condition $\left(1 \% \mathrm{O}_{2}\right)$ for 2 days. Number of surviving cells after treatment was determined by crystal violet staining method. Data are expressed as mean \pm SD from three independent experiments, and significant differences from control are shown by ${ }^{* * *} \mathrm{p}<0.001$. (B) Chemical structure of chrysin and tectochrysin.

CTTGTCAC-3'. $\beta$-actin primer (fwd) 5'-AAG TGT GAC GTT GAC ATC CGT AA-3'; and $\beta$-actin primer (rev) 5'-TGC CTG GGT ACA TGG TGG TA-3'. PCR reaction was started by an initial activation step at $95^{\circ} \mathrm{C}$ for $15 \mathrm{~min}$, followed by 40 cycles comprising denaturation at $94^{\circ} \mathrm{C} / 15 \mathrm{sec}$, annealing at $55^{\circ} \mathrm{C} / 30 \mathrm{sec}$, and extension at $72^{\circ} \mathrm{C} / 30 \mathrm{sec}$. Expression level of the VEGF gene was normalized to $\beta$-actin gene, and calculated from crossing point $(\mathrm{Cp})$ value of the sample, relative gene expression level $=2^{(\mathrm{Cp} \text { actin }-\mathrm{Cp} \text { target })}$. The relative change in gene expression compared with untreated normoxic cells was expressed as fold change, calculated by $2^{-\Delta \Delta C_{p}}$ method.

Spontaneous metastasis mouse model. Balb/c mice (6-weekold female) were purchased from Sankyo Lab Service Co. (Hamamatsu, Japan). Experiments were conducted in accordance with institutional guidelines and approval of University of Toyama Animal Experimental Ethics Committee. Cell suspensions $\left(5 \times 10^{5}\right.$ cells) were injected into mammary fat pads on day 0 . Tumors were measured every other day (length and width) using a caliper. Daily oral administration (p.o.) of chrysin suspended in $0.5 \%$ carboxymethyl cellulose began on day 1 after tumor inoculation. DR5 mAb (10 $\mu \mathrm{g}$ /mouse) was intraperitoneally (i.p.) injected on day 10 and day 14 after tumor inoculation. Primary tumors were excised on day 18 , weighed and fixed in $10 \%$ formalin. After sacrificing the mice on day 32 , lungs were collected and fixed in Bouin's solution $(0.9 \%$ picric acid, $9 \%$ formaldehyde, $5 \%$ acetic acid). Number of metastatic colonies on surface of the lungs was counted. Size of primary tumors and metastatic colonies was measured using a caliper square along the longer axes $(a)$ and shorter axes $(b)$, and tumor volume was calculated by the following formula; tumor volume $\left(\mathrm{mm}^{3}\right)=\mathrm{ab}^{2} / 2$. The volume of metastatic colonies was categorized into 3 sizes; small $\left(<0.5 \mathrm{~mm}^{3}\right)$, medium $\left(0.5-1.5 \mathrm{~mm}^{3}\right)$, and large $\left(>1.5 \mathrm{~mm}^{3}\right)$. Metastatic burden was determined from total volume of lung metastatic colonies. Data are expressed as mean \pm SD of 10 mice per group.

Statistical analysis. For in vitro experiments, data are expressed as mean $\pm \mathrm{SD}$, and analyzed by Student's two-tailed t-test to determine the significance of differences between groups. For in vivo experiments, the significance of differences between groups was analyzed by analysis of variance (ANOVA), and the means were compared by using Tukey, with a p-value $<0.05$ being considered significant.

\section{Results}

Inhibitory effect of Thai propolis extract and chrysin on hypoxic survival of breast cancer cells. We first examined the effect of Thai propolis extract against hypoxic survival of 4T1 cells. Pretreatment with propolis extract $(10-100 \mu \mathrm{g} / \mathrm{ml})$ for $30 \mathrm{~min}$ before exposure to hypoxia $\left(1 \% \mathrm{O}_{2}\right)$ for 2 days decreased hypoxic cell survival in a concentration-dependent manner (Fig. 1A). Next, the two major constituents present in Thai propolis extract, chrysin and tectochrysin (Fig. 1B) were examined. Chrysin treatment showed a concentrationdependent decrease in hypoxic cell survival, with $28-74 \%$ inhibition observed at 40-100 $\mu \mathrm{M}$ chrysin, while tectochrysin did not show inhibition at the highest soluble concentration $(60 \mu \mathrm{M})$ (Fig. 1C). These results indicate that chrysin contributes to the inhibitory effect of Thai propolis extract on hypoxic cell survival.

Effect of chrysin on hypoxia-induced activation of multiple cell signaling pathways and VEGF expression. We further explored effect of chrysin on hypoxia-induced activation of multiple cell signaling pathways that contribute to cell survival, including HIF-1, STAT3, Akt, ERK, and NF- $\mathrm{kB}$. 4T1 cells were pretreated with $60-100 \mu \mathrm{M}$ chrysin for $30 \mathrm{~min}$ before exposure to hypoxia for 6-24 h. HIF-1 $\alpha$ protein stabilization and hypoxia-induced phosphorylation of ERK and p65 NF- $\kappa \mathrm{B}$ were not inhibited by chrysin treatment (Fig. 2A). In contrast, hypoxia-induced STAT3 tyrosine phosphorylation was markedly inhibited by chrysin, in a dose- and time-dependent manner, while marginal decrease in Akt phosphorylation was observed only at the highest concentration test $(100 \mu \mathrm{M})$ (Fig. 2A), suggesting that STAT3 was primary target of chrysin rather than Akt.

Specific inhibitors of STAT3 (cucurbitacin-I, $2 \mu \mathrm{M}$ ), PI3K (LY294002, $25 \mu \mathrm{M}$ ), ERK (PD98059, $25 \mu \mathrm{M}$ ), and NF-кB (IKK-2 inhibitor IV, $10 \mu \mathrm{M}$ ), were used to evaluate the contribution of the signaling pathways on hypoxic survival of 4T1 cells. Pretreatment with inhibitors for $30 \mathrm{~min}$ before hypoxic exposure for 2 days revealed that hypoxic cell survival was 

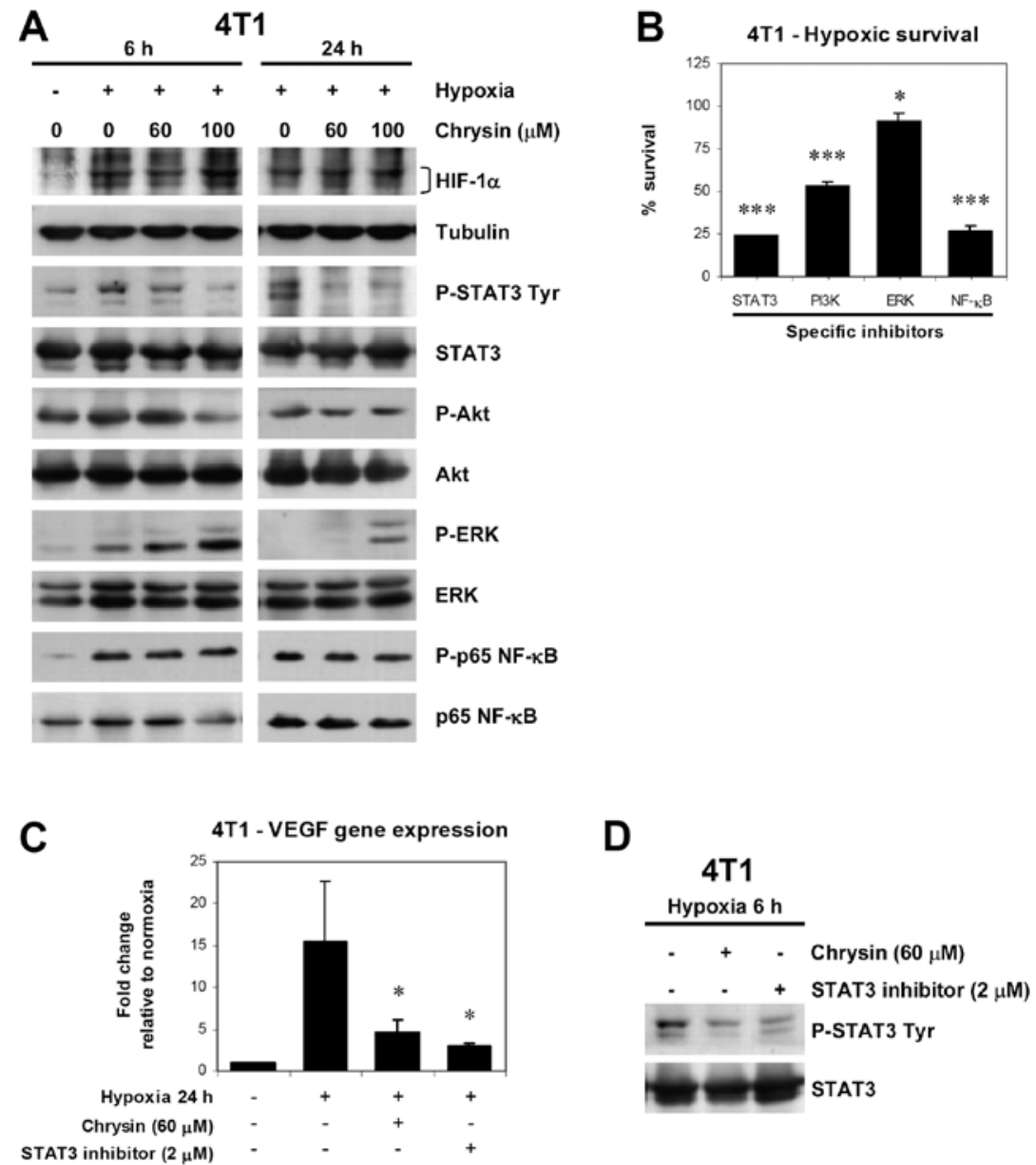

Figure 2. Effect of chrysin on hypoxia-induced activation of multiple signaling pathways and VEGF gene expression. (A) Immunoblot analysis of HIF-1 $\alpha$ stabilization and phosphorylation of multiple signaling pathways in 4T1 under hypoxia $\left(1 \% \mathrm{O}_{2}\right)$. Cells were treated with chrysin at indicated concentrations for $30 \mathrm{~min}$ before incubation under hypoxic condition for 6 or $24 \mathrm{~h}$, after which whole cell lysates were analyzed by immunoblotting. (B) Effect of specific inhibitors of signaling pathways, including STAT3 (cucurbitacin-I, $2 \mu \mathrm{M}$ ), PI3K (LY294002, $25 \mu \mathrm{M}$ ), ERK (PD98059, $25 \mu \mathrm{M}$ ), and NF- $\mathrm{B}$ (IKK-2 inhibitor IV, $10 \mu \mathrm{M}$ ), on hypoxic survival of $4 \mathrm{~T} 1$ cells. The cells were treated with test inhibitor for 30 min before incubation under hypoxic condition for 2 days. Number of surviving cells after treatment was determined by crystal violet staining method. (C) $4 \mathrm{~T} 1$ cells were treated with chrysin for 30 min before incubation under hypoxia $\left(1 \% \mathrm{O}_{2}\right)$ for $24 \mathrm{~h}$, VEGF mRNA level was determined by qRT-PCR, and normalized to $\beta$-actin. Change in gene expression compared with normoxic control is expressed as fold change. Data are expressed as mean \pm SD from three independent experiments, and significant difference from hypoxic control are shown by ${ }^{*} \mathrm{p}<0.05,{ }^{* * *} \mathrm{p}<0.001$. (D) Inmmunoblot analysis of STAT3 phosphorylation confirms inhibitory effect of chrysin and STAT3 inhibitor on hypoxiainduced STAT3 phosphorylation in 4T1 cells. Cells were treated with test compound for 30 min before incubation under hypoxic condition for 6 h, after which whole cell lysates were analyzed by immunoblotting.

inhibited by inhibitors of STAT3, Akt, and NF- $\kappa$ B pathways, while ERK inhibitor showed marginal effect (Fig. 2B). These results indicate the important role of STAT3, Akt, and NF- $\kappa$ B pathways in hypoxic survival of 4T1 cells. Moreover, STAT3 inhibitor treatment mimics the effect of chrysin, suggesting that STAT3 inhibition is the mechanism underlying inhibitory effect of chrysin on hypoxic survival of 4T1 cells.

VEGF has been shown to be an autocrine survival factor for breast cancer cells under hypoxia (12). We examined the effect of chrysin on hypoxia-induced VEGF gene expression in 4T1 cells, in comparison to a STAT3 inhibitor (cucurbitacin-I). The cells were pretreated with chrysin $(60 \mu \mathrm{M})$ or STAT3 inhibitor $(2 \mu \mathrm{M})$ for $30 \mathrm{~min}$ before exposure to hypoxia for $24 \mathrm{~h}$. qRT-PCR analysis revealed that hypoxia increased VEGF mRNA levels in 4T1 cells by 16-fold higher than normoxic cells (Fig. 2C). Chrysin decreased VEGF mRNA levels in hypoxic 4T1 cells, similar to that observed with STAT3 inhibitor treatment, by 71 and $81 \%$ inhibition, respectively, compared with control hypoxic cells (Fig. 2C). The reduction of VEGF expression by chrysin and STAT3 inhibitor was correlated with decrease in STAT3 tyrosine phosphorylation levels under hypoxia (Fig. 2D). Taken together, the results indicate that STAT3 inhibition is likely to be a mechanism of action of chrysin for decreasing hypoxia-induced VEGF expression in 4T1 cells, and this might contribute to the effect of chrysin on hypoxic survival.

Chrysin suppresses growth of lung metastatic colonies in vivo. Since hypoxia and angiogenesis contribute to tumor progression and metastatic formation (7), chrysin was further studied in 4T1 spontaneous metastasis model. The experimental treatment protocol (Fig. 3A) did not affect body weight of the mice (data not shown). The effect of treatments was evaluated from both primary tumor growth and metastatic burden. Chrysin (100 and $250 \mathrm{mg} / \mathrm{kg}$ daily) had no significant effect on primary tumor growth (Fig. 3B and C). However, metastatic burden was largely decreased by chrysin, in a dose-dependent manner, and significant suppression was observed with the highest dose of 
A
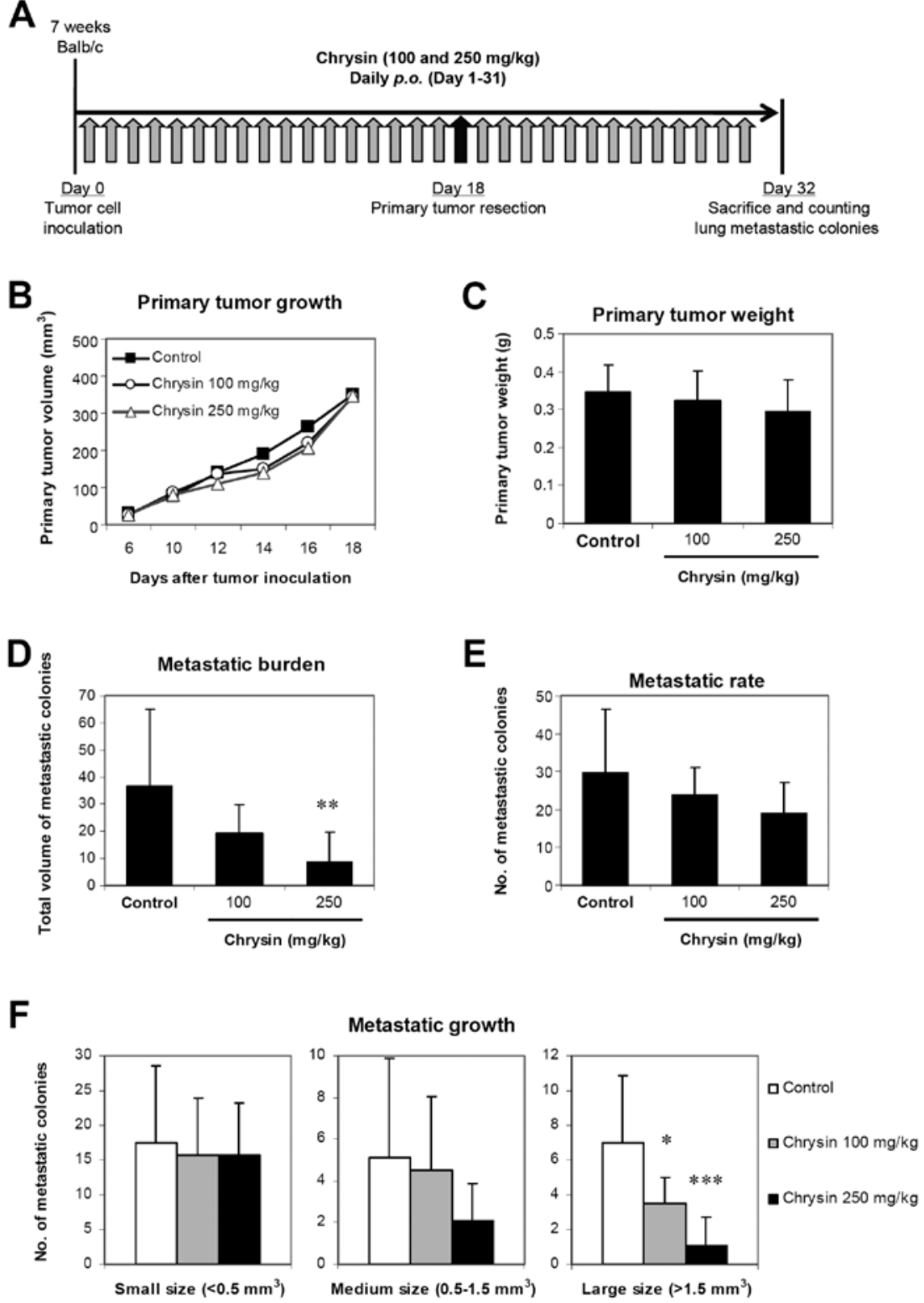

Figure 3. Antimetastatic effect of chrysin in vivo. (A) Experimental treatment protocol for 4T1 spontaneous lung metastasis. 4T1 cells were inoculated into mammary fat pad of Balb/c mice. Chrysin $(100$ and $250 \mathrm{mg} / \mathrm{kg}$ ) was orally administered daily until day 31. Primary tumors were resected on day 18 , and mice were sacrificed on day 32. (B and C) Effect of chrysin on primary tumor growth and weight. Size of primary tumors was periodically measured and weight was determined after tumor resection. (D-F) Effect of chrysin on metastatic burden (total volume of metastatic colonies), metastatic rate (total number of metastases), and metastatic growth (size of metastases). Lung metastatic colonies were counted and categorized, according to their volume, into small $\left(<0.5 \mathrm{~mm}^{3}\right)$, medium $\left(0.5-1.5 \mathrm{~mm}^{3}\right)$, and large $\left(>1.5 \mathrm{~mm}^{3}\right)$. Data are expressed as mean $\pm \mathrm{SD}(\mathrm{n}=10)$, and significant differences from control are shown by ${ }^{*} \mathrm{p}<0.05,{ }^{* *} \mathrm{p}<0.01,{ }^{* * *} \mathrm{p}<0.001$.

chrysin treatment (Fig. 3D). Reduction of metastatic burden might result from either decrease in metastatic rate (number of metastatic colonies) or metastatic growth (size of metastatic colonies), or both. Chrysin tended to decrease metastatic rate but without statistical significance (Fig. 3E). Suppressive effect of chrysin on metastatic growth was observed by decreased number of medium and large size metastatic colonies, in a dose-dependent manner, and significant reduction was clearly observed with large size metastatic colonies (Fig. 3F). These results reveal the antimetastatic activity of chrysin in vivo by inhibiting the growth of metastatic colonies.

Chrysin potentiates antimetastatic activity of the DR5 agonistic $m A b$. In addition to therapeutic effect on primary tumor, DR5 mAb also expresses antimetastatic activity in mouse models (2). We evaluated the potential of chrysin as an adjuvant for antimetastatic activity of DR5 mAb. Since 4T1 cells are sensitive to apoptosis induced by DR $5 \mathrm{mAb}$, low dose treatment of DR5 mAb $(10 \mu \mathrm{g} /$ mouse, $\mathrm{x} 2)$ was used instead of therapeutic doses $(200 \mu \mathrm{g} / \mathrm{mouse}, \mathrm{x} 3)$ used previously (2), in order to avoid metastasis reduction by massive elimination. DR5 mAb alone significantly suppressed primary tumor growth as shown by reduction in primary tumor size and weight, compared with control (Fig. 4B and C). Combination of DR5 mAb + chrysin $(250 \mathrm{mg} / \mathrm{kg} / \mathrm{d})$ tended to be more suppressive, but no statistical difference between DR5 $\mathrm{mAb}$ alone and the combination treatment was observed (Fig. 4C). Antimetastatic activity of DR5 mAb was 

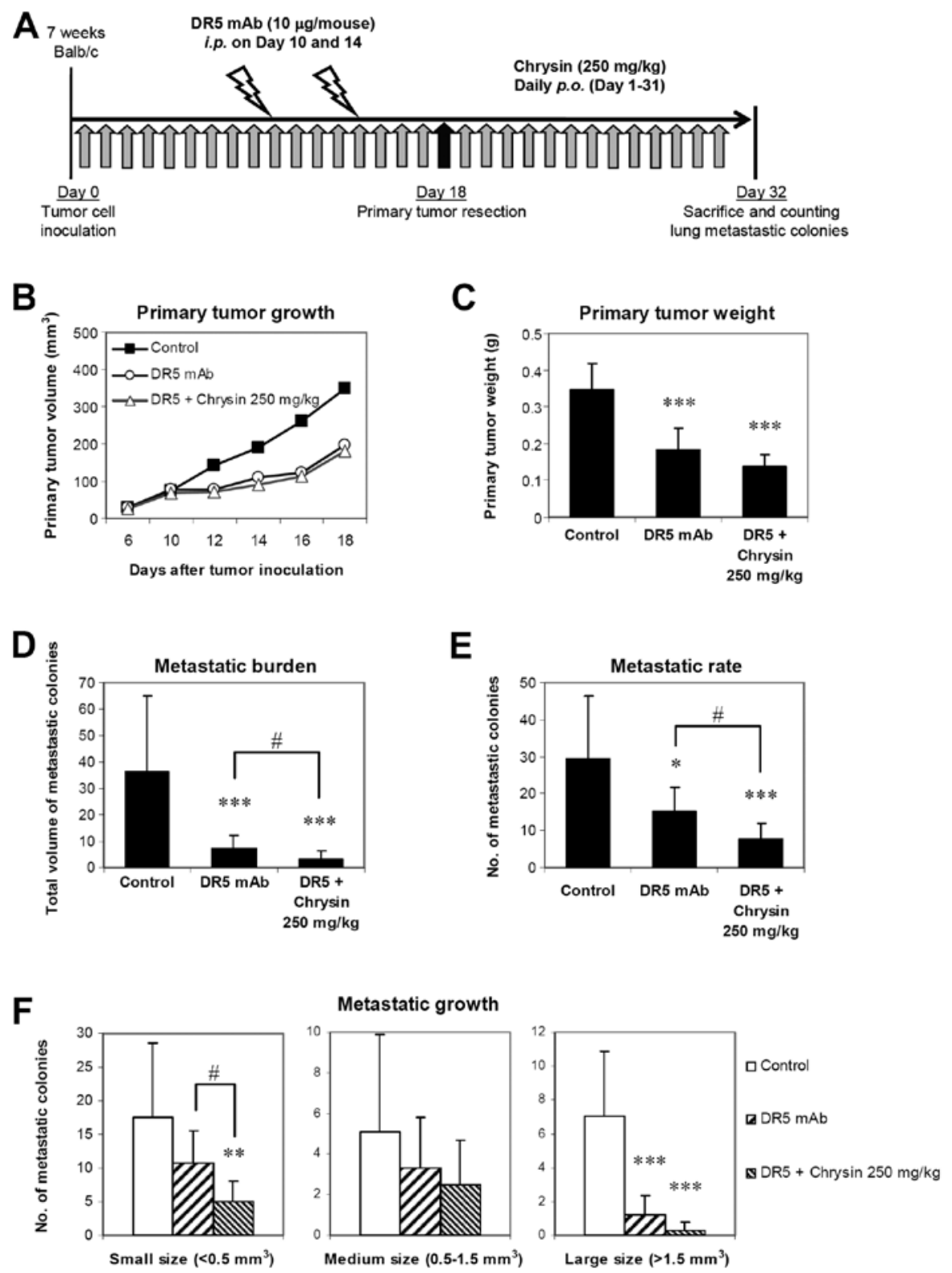

Figure 4. Effect of chrysin and DR5 agonistic mAb combination treatment in vivo. (A) Experimental treatment protocol for 4T1 spontaneous lung metastasis. $4 \mathrm{~T} 1$ cells were inoculated into mammary fat pad of Balb/c mice. Chrysin $(250 \mathrm{mg} / \mathrm{kg})$ was orally administered daily until day 31 . DR5 agonistic mAb (10 $\mu \mathrm{g} /$ mouse) was i.p. administered on day 10 and 14. Primary tumors were resected on day 18, and mice were sacrificed on day 32 . (B and C) Effect of combination treatment on primary tumor growth and weight. Size of primary tumors was periodically measured and weight was determined after tumor resection. (D-F) Effect of combination treatment on metastatic burden (total volume of metastatic colonies), metastatic rate (total number of metastatic colonies), and metastatic growth (size of metastatic colonies). Lung metastatic colonies were counted and categorized, according to their volume, into small $\left(<0.5 \mathrm{~mm}^{3}\right)$, medium $\left(0.5-1.5 \mathrm{~mm}^{3}\right)$, and large $\left(>1.5 \mathrm{~mm}^{3}\right)$. Data are expressed as mean $\pm \mathrm{SD}(\mathrm{n}=10)$, and significant differences from control are shown by ${ }^{*} \mathrm{p}<0.05$, $\left.{ }^{* *} \mathrm{p}<0.01\right),{ }^{* * *} \mathrm{p}<0.001$. Significant differences between DR5 mAb alone and DR5 + chrysin are shown by ${ }^{\#} \mathrm{p}<0.05$.

revealed by significant decrease in metastatic burden and metastatic rate, and the combination treatment resulted in a significantly greater effect (Fig. 4D and E). DR5 mAb also expressed suppressive effect on metastatic growth, as shown by significant decrease in number of large size metastatic colonies, with greater effect being observed in combination treatment (Fig. 4F). Moreover, the effect of DR5 $\mathrm{mAb}$ on the number of small size metastatic colonies was significantly potentiated when DR5 mAb was combined with chrysin (Fig. 4F). Collectively, the results suggested that chrysin per se had a suppressive effect on metastatic growth, and could enhance antimetastatic activity of DR5 $\mathrm{mAb}$ in combination treatment.

\section{Discussion}

In the present study, we demonstrate the ability of chrysin to decrease hypoxic survival of cancer cells, by inhibiting hypoxia-induced STAT3 activation and VEGF expression. We also provide in vivo evidence of the suppressive effect of chrysin on metastatic growth, and a potentiating effect of chrysin when combined with another antimetastatic agent, DR5 mAb. To our knowledge, this is the first study on the antimetastatic effect of chrysin in a spontaneous metastasis mouse model.

Increased VEGF production has been shown to play a role in hypoxic survival of 4T1 cells, and treatment with VEGF neutralizing antibody can decrease hypoxic survival rate of cells (12). 


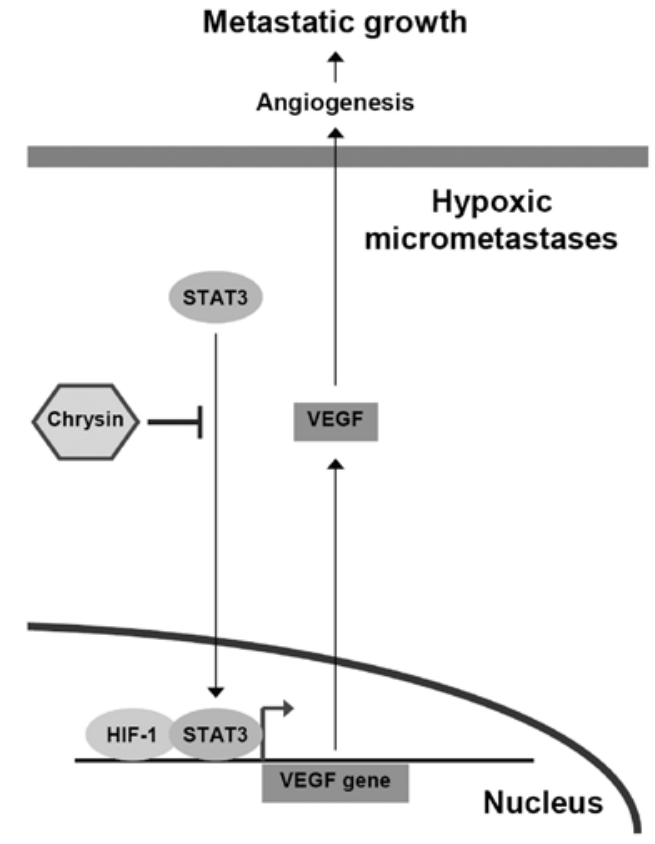

Figure 5. Proposed mechanism for suppressive effect of chrysin on metastatic growth. Chrysin inhibits STAT3 activation in hypoxic micrometastases, leading to abrogation of hypoxia-induced VEGF expression and angiogenesis, and subsequent suppression of metastatic growth.

Consistent with previous studies, our results showed that treatment with either chrysin or STAT3 inhibitor (cucurbitacin-I), which inhibited hypoxia-induced VEGF expression, could decrease hypoxic survival of 4T1 cells.

In hypoxic cells, tyrosine phosphorylated STAT3 forms a complex with HIF-1 $\alpha$ at the VEGF promoter, and this complex is important for upregulation of VEGF gene expression in hypoxic cells (11). Our results clearly show that chrysin, as well as a STAT3 inhibitor, could abrogate hypoxia-induced VEGF gene expression of 4T1 cells, through inhibition of STAT3 tyrosine phosphorylation, without decreasing HIF-1 $\alpha$ protein levels. Chrysin has been shown to decrease HIF-1 $\alpha$ protein levels in hypoxic DU145 human prostate cancer cells, thus abrogating insulin-induced HIF-1 $\alpha$ protein stabilization in normoxic DU145 cells, via inhibition of Akt phosphorylation (16).

In a previous study, STAT3 signaling was not investigated, and the inhibitory effect of chrysin on Akt-modulated HIF-1 $\alpha$ protein stability was shown only in the insulin-stimulated normoxic cells, but the mechanism was not tested in hypoxic cells (16). In 4T1 cells, the inhibition of hypoxia-induced VEGF expression and STAT3 activation by chrysin were observed at a concentration lower than that affecting Akt phosphorylation (Fig. 2A), suggesting that STAT3 was the primary target rather than Akt in our model. Additionally, a recent study shows that chrysin inhibits STAT3-mediated VEGF expression, which contributes to suppression of IL-6induced angiogenesis by chrysin in human endothelial cells, as well as in ovo model (23). Collectively, evidence indicates that chrysin possesses ability to inhibit angiogenesis, at least partly, through inhibiting STAT3-mediated VEGF expression.

In our metastasis mouse model, daily oral administration of chrysin predominantly inhibited metastatic growth, rather than primary tumor growth. Chrysin has a low oral bioavailability in humans and rats, due to extensive metabolism to chrysin sulphate and chrysin glucuronide, and efflux into intestine (24). Thus, the concentration of chrysin within primary tumors might be low, especially during early treatment time, when the primary tumor is growing. Another low oral bioavailability flavonoid, genistein, also shows a significant suppressive effect on lung metastatic burden, while marginally decreasing primary tumor growth at mammary fat pads, in breast cancer-harboring mice receiving genisteinsupplemented diet (25), similar to that observed in our chrysin treatment.

Our results revealed that chrysin significantly suppressed metastatic growth (size of metastatic colonies), while rate of metastasis (total number of metastatic colonies) was marginally decreased, suggesting that chrysin interfered with growth after the tumor cells reached their metastatic sites. Since progression of micrometastases to macrometastases requires angiogenesis (9), blocking VEGF-mediated angiogenesis may suppress metastatic growth. This is supported by results showing that treatment with a soluble VEGF decoy receptor (VEGF-Trap) leads to decrease in the size of established lung metastases of Wilms tumor cells, without changing the number of metastases (26). In another study, liver metastatic growth of colon adenocarcinoma was shown to be suppressed by rapamycin treatment, which affects both VEGF production of tumor cells and VEGF-response of endothelial cells (27). Taken together, we suggest that the suppression of metastatic growth by chrysin was, at least in part, due to interruption of angiogenesis in hypoxic micrometastases, by inhibiting hypoxia-induced STAT3 activation and VEGF expression.

Control of metastatic growth using hypoxia-selective chemotherapy as adjuvant appears to be an effective strategy, since a marked reduction of metastatic burden was found in lungs of KHT sarcoma-harboring mice receiving postradiotherapy treatment with a hypoxia-activated cytotoxin NLCQ-1, when hypoxic micrometastases were evident in lungs (28). In our study, combination treatment of chrysin and DR5 $\mathrm{mAb}$ was more effective than each single agent in reducing both metastatic rate and metastatic growth, suggesting that chrysin might be useful as an adjuvant in controlling metastatic progression.

In conclusion, chrysin decreased hypoxic survival, inhibited STAT3 activation, and diminished VEGF expression in hypoxic cancer cells, leading to abrogation of hypoxia-induced angiogenesis and resulting in suppression of metastatic growth (Fig. 5). This study also suggests that chrysin is a potential chemopreventive as well as an adjuvant agent, that can be used in combination with other antimetastatic agents to control metastatic progression of tumors.

\section{Acknowledgements}

This work was supported by the Thailand Research Fund, TRG5380026 (K. Lirdprapamongkol), a Japanese-Thai Collaborative Scientific Research Fellowship (JSPS-NRCT), and a research grant from the Chulabhorn Research Institute. We would like to thank Ms. Yue Zhou, Dr Orawin Prangsaengtong, Dr Rudee Surarit, Ms. Korakot Atjanasuppat and Ms. Khajeelak Chiablaem for their assistance. 


\section{References}

1. Chambers AF, Groom AC and MacDonald IC: Dissemination and growth of cancer cells in metastatic sites. Nat Rev Cancer 2: 563-572, 2002

2. Takeda K, Yamaguchi N, Akiba H, et al: Induction of tumorspecific T cell immunity by anti-DR5 antibody therapy. J Exp Med 199: 437-448, 2004

3. Hattori $\mathrm{H}$, Okuda $\mathrm{K}$, Murase $\mathrm{T}$, et al: Isolation, identification, and biological evaluation of HIF-1-modulating compounds from Brazilian green propolis. Bioorg Med Chem 19: 5392-5401, 2011

4. Brizel DM, Scully SP, Harrelson JM, et al: Tumor oxygenation predicts for the likelihood of distant metastases in human soft tissue sarcoma. Cancer Res 56: 941-943, 1996.

5. Hockel M, Schlenger K, Aral B, Mitze M, Schaffer U and Vaupel P: Association between tumor hypoxia and malignant progression in advanced cancer of the uterine cervix. Cancer Res 56: 4509-4515, 1996.

6. Li XF, Carlin S, Urano M, Russell J, Ling CC and O'Donoghue JA: Visualization of hypoxia in microscopic tumors by immunofluorescent microscopy. Cancer Res 67: 7646-7653, 2007.

7. Li XF and O'Donoghue JA: Hypoxia in microscopic tumors. Cancer Lett 264: 172-180, 2008.

8. Iglesias P, Fraga M and Costoya JA: Defining hypoxic microenvironments by non-invasive functional optical imaging. Eur J Cancer 49: 264-271, 2013.

9. McDonnell CO, Hill AD, McNamara DA, Walsh TN and Bouchier-Hayes DJ: Tumour micrometastases: the influence of angiogenesis. Eur J Surg Oncol 26: 105-115, 2000.

10. Minet E, Michel G, Mottet D, Raes M and Michiels C: Transduction pathways involved in Hypoxia-Inducible Factor-1 phosphorylation and activation. Free Radic Biol Med 31: 847-855, 2001.

11. Jung JE, Lee HG, Cho IH, et al: STAT3 is a potential modulator of HIF-1-mediated VEGF expression in human renal carcinoma cells. FASEB J 19: 1296-1298, 2005.

12. Barr MP, Bouchier-Hayes DJ and Harmey JJ: Vascular endothelial growth factor is an autocrine survival factor for breast tumour cells under hypoxia. Int J Oncol 32: 41-48, 2008.

13. Zhang J, Lu A, Beech D, Jiang B and Lu Y: Suppression of breast cancer metastasis through the inhibition of VEGF-mediated tumor angiogenesis. Cancer Ther 5: 273-286, 2007.

14. Sun LP, Chen AL, Hung HC, et al: Chrysin: a histone deacetylase 8 inhibitor with anticancer activity and a suitable candidate for the standardization of Chinese propolis. J Agric Food Chem 60: 11748-11758, 2012.

15. Zhao X, Shu G, Chen L, Mi X, Mei Z and Deng X: A flavonoid component from Docynia delavayi (Franch.) Schneid represses transplanted $\mathrm{H} 22$ hepatoma growth and exhibits low toxic effect on tumor-bearing mice. Food Chem Toxicol 50: 3166-3173, 2012.
16. Fu B, Xue J, Li Z, Shi X, Jiang BH and Fang J: Chrysin inhibits expression of hypoxia-inducible factor-1alpha through reducing hypoxia-inducible factor-1alpha stability and inhibiting its protein synthesis. Mol Cancer Ther 6: 220-226, 2007.

17. Wagner H, Chari VM and Sonnenbichler J: 13C-NMR-spektren natürlich vorkommender flavonoide. Tetrahedron Lett 17: 1799-1802, 1976. (In German)

18. Gaydou E and Bianchini J: Etudes de composés flavoniques. I. Syntheses et propriétés (UV, RMN du 13C) de quelques flavones. Bull Soc Chim Fr II: 43-47, 1978. (In French)

19. Lirdprapamongkol K, Mahidol C, Thongnest S, et al: Antimetastatic effects of aqueous extract of Helixanthera parasitica. $J$ Ethnopharmacol 86: 253-256, 2003.

20. Lirdprapamongkol K, Chiablaem K, Sila-Asna M, Surarit R, Bunyaratvej A and Svasti J: Exploring stemness gene expression and vasculogenic mimicry capacity in well- and poorly-differentiated hepatocellular carcinoma cell lines. Biochem Biophys Res Commun 422: 429-435, 2012.

21. Mitra SK, Mikolon D, Molina JE, et al: Intrinsic FAK activity and Y925 phosphorylation facilitate an angiogenic switch in tumors. Oncogene 25: 5969-5984, 2006.

22. Yang H, Xu Z, Iuvone PM and Grossniklaus HE: Angiostatin decreases cell migration and vascular endothelium growth factor (VEGF) to pigment epithelium derived factor (PEDF) RNA ratio in vitro and in a murine ocular melanoma model. Mol Vis 12: 511-517, 2006.

23. Lin CM, Shyu KG, Wang BW, Chang H, Chen YH and Chiu JH: Chrysin suppresses IL-6-induced angiogenesis via down-regulation of JAK1/STAT3 and VEGF: an in vitro and in ovo approach. J Agric Food Chem 58: 7082-7087, 2010.

24. Walle T, Otake Y, Brubaker JA, Walle UK and Halushka PV: Disposition and metabolism of the flavonoid chrysin in normal volunteers. Br J Clin Pharmacol 51: 143-146, 2001.

25. Vantyghem SA, Wilson SM, Postenka CO, Al-Katib W, Tuck AB and Chambers AF: Dietary genistein reduces metastasis in a postsurgical orthotopic breast cancer model. Cancer Res 65: 3396-3403, 2005.

26. Huang J, Frischer JS, Serur A, et al: Regression of established tumors and metastases by potent vascular endothelial growth factor blockade. Proc Natl Acad Sci USA 100: 7785-7790, 2003.

27. Guba M, von Breitenbuch P, Steinbauer M, et al: Rapamycin inhibits primary and metastatic tumor growth by antiangiogenesis: involvement of vascular endothelial growth factor. Nat Med 8: 128-135, 2002

28. Lunt SJ, Cawthorne C, Ali M, et al: The hypoxia-selective cytotoxin NLCQ-1 (NSC 709257) controls metastatic disease when used as an adjuvant to radiotherapy. Br J Cancer 103: 201-208, 2010. 